\title{
A Case Study: Broadband Over Powerline for Rural Area Deployment in Sarawak
}

\author{
Nancy. $\mathrm{B}^{1, *}$, Gary Loh C.W $W^{1}$, M. Razi. Bazin ${ }^{2}$ and Panceras.T. $\mathrm{M}^{3}$ \\ ${ }^{1}$ University College of Technology Sarawak, School of Computing and Creative Media, 96000 Sibu, Sarawak, Malaysia \\ ${ }^{2}$ Datasonic Technolgies Sdn Bhd.,Damasara Geights, 50490, Kuala Lumpur, Malaysia \\ ${ }^{3}$ Bintulu, Sarawak, Malaysia
}

\begin{abstract}
Broadband over powerline (BPL) is a technology that allows connectivity to internet connection riding via the low tension (LT) power line communication (PLC). A hybrid BPL technology was proposed to the rural area of Sarawak as an alternative option to expand the internet connection without the need to reform a new pathway for internet connectivity. The data signal is transmitted via a communication tower to the access point(s) that is mounted on an electricity pole that provides a low voltage (LV) line. There are three types of custom-designed equipment that has been integrated into the hybrid BPL: the Head End (HE), the Time Division Repeater (TDR) and the Customer Premise Equipment (CPE). Two longhouses at the Bawang Assan, Sarawak settlement has been chosen to initiate the pilot project that required the cooperation of the technology provider, power producer, and the internet service provider. This paper presents a proof of concept (POC) on the deployment, advantages, and limitations for the BPL in a rural setting.
\end{abstract}

\section{Introduction}

The concept of Broadband over Power Line (BPL) were being introduced as an expansion of broadband services over the power line utility [1]. It can transform the standard electric power grid into a communication route; opening pathway for data signals traverse across the utility devices on the grid toward the consumer outlet. Riding on the existing power line, BPL utilise the inplace electrical infrastructure; an advantage for the rural areas where infrastructure upgrades are the most costprohibitive. In the rural area of Sarawak, Malaysia, 1 kilometre of fiberisation alone can cost up to RM30,000. Such demand not only expensive but the population demand will have to make up for such progression for basic Digital Subscriber (DSL) deployment. In 2018, the Chief Minister of Sarawak has urged the growth and advancement of Sarawak's Digital Economy [2]. Thus, Information and Communication Technology (ICT) development are vital to narrow the urban-rural divide.

The electricity output frequency in Malaysia is measured at $50 \mathrm{~Hz}$. Meanwhile, BPL operates at the frequency range of $1-80 \mathrm{MHz}$ by coupling the radio frequency to the electrical power lines [1]. Accordingly, the oscillation of the electric current and the data signals does not interfere with each other significantly to disrupt the data transmission. Moreover, the BPL technology adopted the Orthogonal Frequency Division Multiplexing (OFDM) modulation technique which divided a single channel into several subcarriers channels with an orthogonally overlapping spectrum to reduce interference and crosstalk. Nevertheless, the data signals are only suitable to be a carrier in low-voltage (LV) or medium-voltage (MV) distribution network [3]. Usually, the data signal are dropped at the MV or LV lines, while high voltage (HV) line are unsuitable due to interferences caused by the spike of electricity [3].

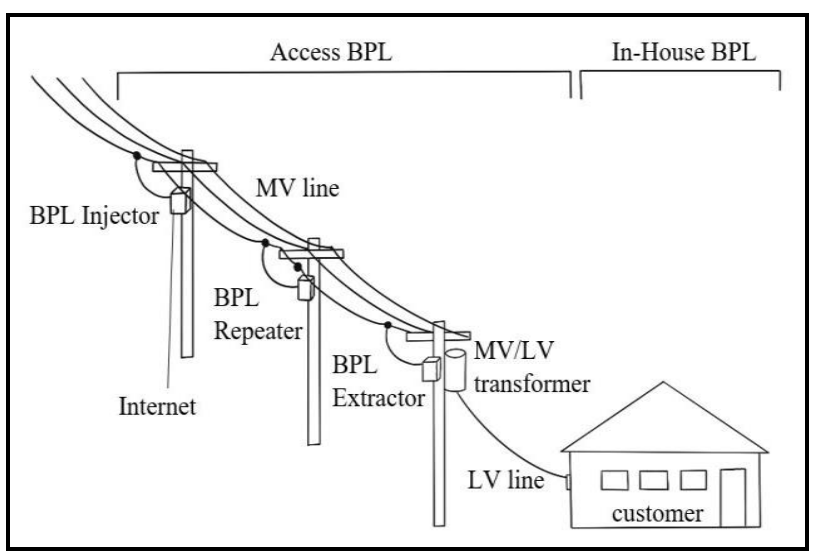

Fig. 1. A typical BPL architecture [1].

Still, the signal would not travel far due to signal degradation; a repeater can further amplify the data before it reaches the destination of its final consumer. At the user residential, the BPL modem were plugged into the wall socket and a linking to the computer completes the connection wired or wirelessly [4]. The connection is capable to produce approximately $2-5 \mathrm{Mbps}$ of communication speed [4]. There are two predominant types of BPL, the in-house BPL and the access BPL. An in-house BPL allows a device to connect to a local area 
network (LAN) directly through the LV electric grid inside the premises. Meanwhile, the access BPL delivers both broadband and power from the electrical sub-station to the given premises by the electricity service provider [4].

\section{Related Works}

BPL has been proposed as a solution to internet access, especially in which Digital Subscriber Line (DSL) or fiber cable service is not possible. There are several variances of development or research project that has been taken place to studies the feasibility of such deployment. In Russia, MegaFon the telecom operator has collaborated with utility company using power lines for fiber-optic networks in Siberia [5]. Meanwhile, in Saudi Arabia, the usage of such technology is still in an ongoing process and is projected to be one of the telecommunication solutions by studying the market needs [6]. The Cactel Communication. Ltd in Ghana has successfully deployed an MV pilot project since 2005 [7] and the continuous of the project may be expanded further by their local electricity companies [8]. In India, Corinex Communication a provider of powerline and Coaxial networking products had led to provide internet access to rural villages in India through the BPL technology [9]. Meanwhile, since 2006 the Philippines continued with the BPL services despite a competition from other broadband sectors [10]. In many countries such as Indonesia, Malaysia, Bangladesh and the Middle East BPL can be seen as a viable alternative broadband solution.

\section{The BPL Architecture}

A typical BPL architecture begins from the MV transmission distribution circuit and usually contains four main elements i.e. (a) the injector, (b) the repeater, (c) the coupler, (d) the extractor and (e) the modem [10]. Referring to Figure 1, the three-phase wiring is connected to a MV distribution. The system which is connected to the Internet backbone drops the data of the fiber-optic or digital signaling level 1 (DS1) line downstream. One or more phase lines may branch out from the three-phase lines serving into the customer premises. A grounded neutral conductor is generally located below the phase conductors and runs between distribution transformers that provide LV electric power for customer use. The BPL signals may be injected onto the MV power lines : (1) between two phase conductors; (2) between a phase conductor and the neutral conductor; or (3) onto a single-phase or neutral conductor [11]. Thus, a distinctive BPL architecture will have the following components.

\subsection{The Injector}

It converts the signal on the fiber/DS1 line into the signal format used for transmission over the MV power line. The injectors interface to the MV power lines enable a full-duplex transmission whereby the injector consists of a transmitter, receiver and a signal converter.

\subsection{The Repeater}

As the signal traverse, it may be degraded at some point during the transmission. The repeater will amplify the data to prevent attenuation losses and correction for phase distortion. It takes in the data and repeats it in a new transmission, amplifying it for the next leg of the journey.

\subsection{The Coupler}

The coupler can be used to provide a data path around the transformer either on the MV or LV line. It acts as a bridge allowing the data to transfer without any degradation.

\subsection{The Extractor}

The extractor is used to retrieve signals from the LV distribution transformer and provide the BPL signals to the customers within the service area. Some extractor provides the functionality of a signal strength booster through the LV transformer while other types can relay the BPL signal around the transformer via a coupler. Other kinds of extractors interface with non-BPL devices such as WIFI that can extend the BPL network to the customer premise.

\subsection{The Extractor}

The extractor is used to retrieve signals from the LV distribution transformer and provide the BPL signals to the customers within the service area. Some extractor provides the functionality of a signal strength booster through the LV transformer while other types can relay the BPL signal around the transformer via a coupler. Other kinds of extractors interface with non-BPL devices such as WIFI that can extend the BPL network to the customer premise.

\subsection{The Modem}

The BPL modem is roughly the size of a common power adapter and is capable of handling power noise on a wide spectrum. It can be plugged into a common wall socket and can be accessed either through wired or wireless by the end-user. The BPL modem connects to the powerline transmission medium through a BPL specific (e.g., vendor-proprietary) interface.

The BPL last mile solution can be introduced either by carrying the signal in with the electricity power line or via another method which is allowing the wireless links with a receiving end of an access point. A hybrid BPL incorporates the powerline with wireless transmission [12]. For example, the signal can be injected wirelessly and then using an extractor the signal is transmitted onto the MV power line which delivers it to the end-user. Other types of hybrid BPL captures the 
wireless signal and injects them directly onto the LV power line. The signal is distributed using the LV power line to an in-house wiring (end-user) [13]. The method that has been proposed is similar to the later.

\section{Methodology}

The Bawang Assan community faces a digital divide with very limited internet connectivity despite being relatively near to the Sibu township. It is an Iban settlement comprising of nine longhouses and is approximately $30 \mathrm{~km}$ away from Sibu. Two of the longhouses have been chosen as the implementation site for the pilot BPL project; Rumah Jimbun and Rumah Dennis. A usual Iban longhouse will have multiple Door (bilik; but belong to different families) incorporate together forming a terrace-like housing with an extension of a sharing long-living area (Ruai).

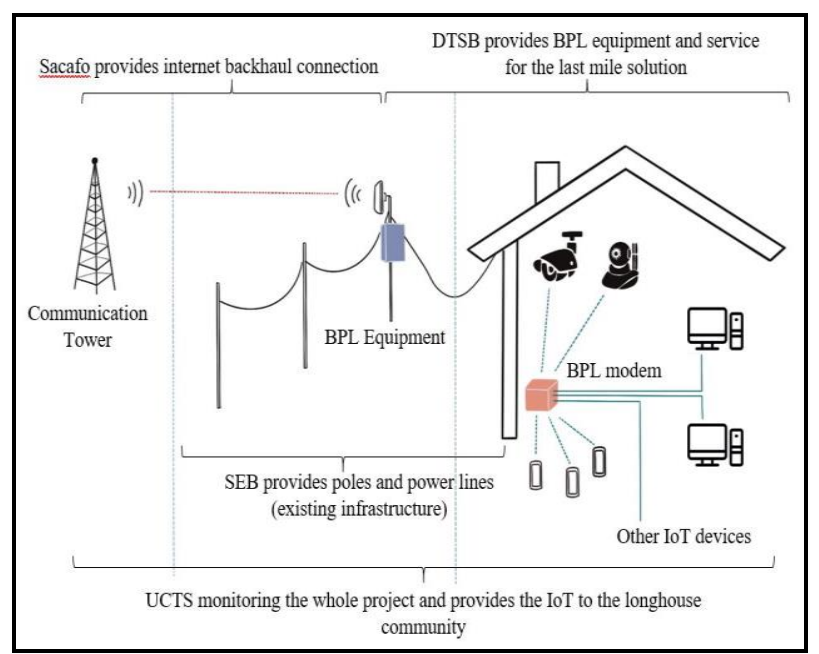

Fig. 2. The BPL pilot project architecture at Bawang Assan.

The pilot project adopted the design of a hybrid BPL architecture, see Figure 2. A communication tower forms a backhaul of the long-range point to point wireless bridge supplying $30 \mathrm{Mbps}$ of internet connection. Before that, approximately $3 \mathrm{~km}$ fiber has to be laid from the nearest service trunk. Then, the signal will transmit over an air distance of $0.7 \mathrm{~km}$ toward two separately located access points, one at the electricity pole near Rumah Jimbun and another electric pole near Rumah Dennis. Both of the access points are attached to the LV line. The access points are required to have a clear Line of Sight (LOS) enabling the long-distance propagation from the communication tower. The nearest LOS pole for Rumah Jimbun is two electrical poles away while Rumah Dennis is one pole away.

The supply voltage in the rural areas for the distribution system outside the longhouse operates at a three-phase, LV 415 volt. Within the premise, the electricity phase out into a single phase, LV 240 volt. There are three main types of BPL equipment that were custom-designed to be integrated into the existing LV network infrastructure to create a communication backbone for internet access, access control, and automation application.

\subsection{Head End (HE)}

Similar to the injector, the HE provides an internet bridge between the internet backhaul and the BPL equipment located at the end-user residence. It manages the flow of data (customer and management), organizes and transmits it according to its router configuration. The $\mathrm{HE}$ also direct the data and remote command securely via the Internet or from any WAN network towards the end-user. See Figure 3.

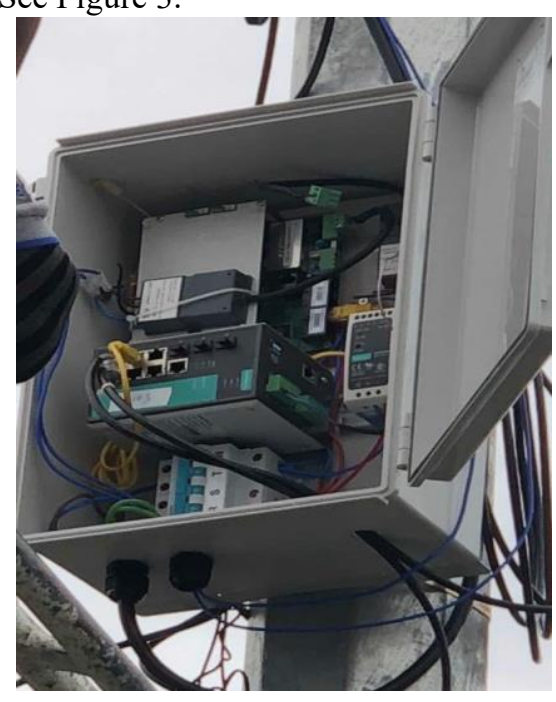

Fig. 3. Head End (HE) on the electrical pole.

\subsection{Time Division Repeater (TDR)}

The TDR act as a repeater for the continuous flow of the data. It maintains the signal strength along with the network before it reaches the end-user. There are two types of TDR being implemented, type 1 TDR and type 2 TDR. The type 2 TDR is installed at the same electricity pole with the HE whilst the type 1 TDR is installed at the customer premise to further boost the signal to the CPE. See Figure 4.

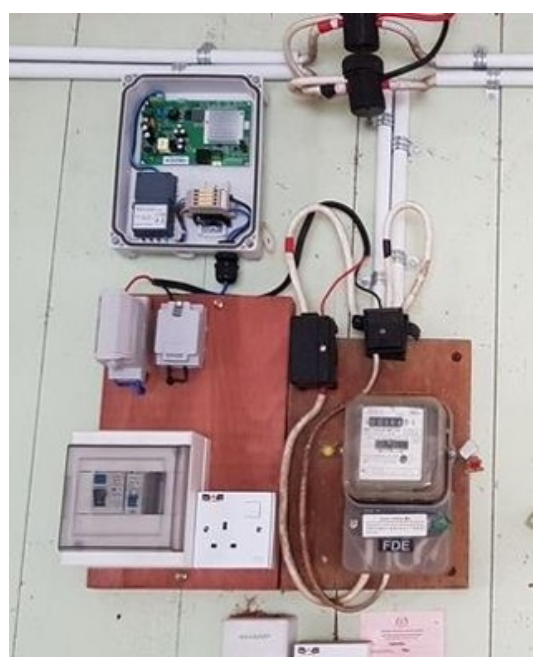

Fig. 4. Type 1 TDR installed at Rumah Dennis.

\subsection{Customer Premise Equipment (CPE)}


The $\mathrm{CPE}$ is equivalent to a BPL modem. It connected to the power socket at the end-user residence which then will allow the end-user to be connected to the internet with a computer or mobile phone. The CPE can be connected via an Ethernet cable or wirelessly. See Figure 5.

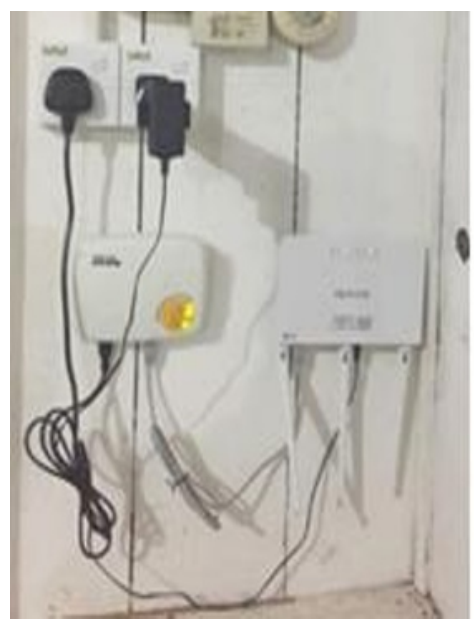

Fig. 5. CPE installed with wireless modem at Rumah Jimbun.

Figure 6 (a) below shows that the HE is connected to the 3 phase power line via a coupler; pin 1 to the neutral line and pin 3 to live line (blue). A circuit breaker was also fitted into the HE; enclose the housing to prevent from short circuit and the Ethernet switch that enables Local Area Network (LAN) connectivity. A type 2 TDR is also being installed on the same electricity pole before the signal is being propagated toward the longhouses. Inside the longhouses, the BPL signal strength level will determine the type 1 TDR (Figure 6 (b)) location to regenerate the low BPL signal and effectively extend the signal to a longer distance reaching the far end of the CPE. There is total number of 13 Doors at Rumah Jimbun and 12 Doors at Rumah Dennis. For Rumah Jimbun, the type 1 TDR was installed at the Ruai; outside of Door 13 and for Rumah Dennis, the type 1 TDR was installed outside of Door 7. Meanwhile, the CPE is install inside individual Door and a Service Set Identifier (SSID) were given.

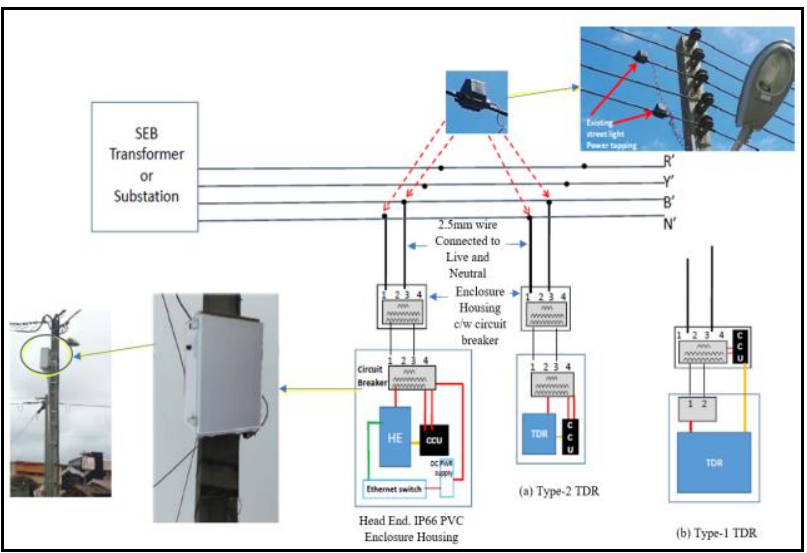

Fig. 6. Schematic diagram of Head End (HE) and Time Division Repeater (TDR) type 1 and type 2.
Figure 7 shows the entire setup of the BPL project in a simplify block diagram. The connection start from the communication tower where the data signal were received by the access point mounted at an existing electricity pole. On the same electrical pole, the HE and type 2 TDR systemize the data signal and re-transmit it to the type 1 TDR which is approximately 80 metres away inside the longhouses. The CPE(s) were installed at a selected power socket of each Bilik. A device called a noise filter is used to obtain the reading of the signalto-noise ratio (SNR) of the power socket. Ideally, the power socket that produce a constant minimum SNR will be selected due to least interferences. The locals were able to access to the internet via their wireless devices.

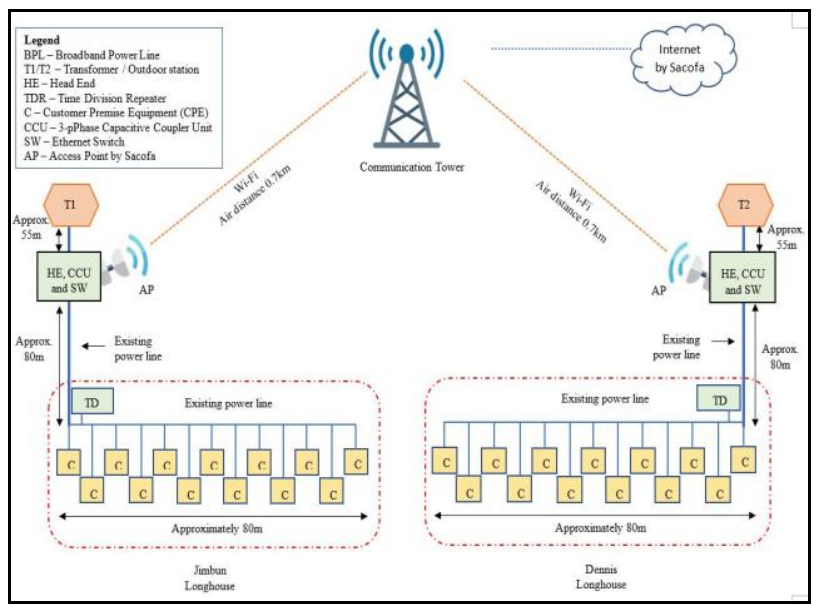

Fig. 7. BPL as the last mile solution at Bawang Assan.

\section{Result and Discussion}

The network performances of the hybrid BPL can be measured based on its upload and download speeds and the latency. The upload speed is the rate in bytes per second (bps) that data is transferred from the user's devices to the remote or local server whereas download speed is the rate in bytes per second (bps) the data can be pull or receive by the user from the designated server. Higher value of upload and download speeds are preferred. Meanwhile, network latency is the time taken for a signal to travel to its destination and back. A lower latency is ideal as latency is essentially a delay between the communication of two devices.

\subsection{Upload and Download Speed}

Table 1 below presents the result for the average upload and download speed taken in the duration of one year. On average the Rumah Jimbun can achieved an average upload speed of 4.16 Mbps and download speed of 6.82 Mbps. Meanwhile, Rumah Dennis can achieved an average upload speed of 5.64 Mbps and download speed of $8.29 \mathrm{Mbps}$. The result for such minor differences is the location of the access point. The access point for Rumah Jimbun was installed at two hops of the electrical pole away due to the requirement of LOS from the communication tower as oppose to Rumah Dennis which 
was only one hop away from the electrical pole. The additional hop might have created an extra interference with longer length thus it accumulate more interferences subsequently effecting the result.

Table 1. Average upload and download speed for Rumah Jimbun and Rumah Dennis

\begin{tabular}{|c|c|c|c|c|}
\hline \multirow{3}{*}{ Month } & \multicolumn{4}{|c|}{ Average (Mbps) } \\
\hline & \multicolumn{2}{|c|}{ Rumah Jimbun } & \multicolumn{2}{|c|}{ Rumah Dennis } \\
\hline & Upload & Download & Upload & Download \\
\hline Jan & 3.51 & 6.76 & 4.6 & 5.70 \\
\hline $\mathrm{Feb}$ & 3.85 & 6.31 & 4.61 & 5.68 \\
\hline Mar & 4.42 & 8.51 & 5.09 & 11.60 \\
\hline April & 3.71 & 11.40 & 5.84 & 10.70 \\
\hline May & 3.61 & 8.89 & 5.91 & 8.36 \\
\hline Jun & 3.78 & 9.73 & 5.81 & 6.93 \\
\hline Jul & 2.71 & 6.15 & 8.13 & 8.36 \\
\hline Aug & 3.22 & 7.45 & 3.14 & 6.08 \\
\hline Sept & 3.28 & 7.82 & 3.13 & 10.1 \\
\hline Oct & 3.07 & 11.50 & 5.09 & 9.30 \\
\hline Nov & 3.77 & 6.31 & 4.82 & 6.54 \\
\hline Dec & 3.16 & 6.82 & 5.19 & 6.48 \\
\hline Average & 4.16 & 6.82 & 5.64 & 8.29 \\
\hline
\end{tabular}

\subsection{Latency}

Network latency is define as the amount of time taken for the data packet to travel from one point to another. Any delay in transmission will also been taken into account, thus, a low delay time will amount into low network latency. The average response time for urban setting is approximately 45 milliseconds from various service provider [14]. Refer to the data collected from Table 2, Rumah Jimbun has an average $216.5 \mathrm{~ms}$ of latency as compare to Rumah Dennis which is $171.17 \mathrm{~ms}$. The higher latency for Rumah Jimbun is also due to the placement of the access point being installed two hop away creating additional intermediate devices from the premises.
Table 2. Average latency for Rumah Jimbun and Rumah Dennis

\begin{tabular}{|c|c|c|}
\hline \multirow{2}{*}{ No } & \multicolumn{2}{|c|}{ Average (millisecond) } \\
\hline & Rumah Jimbun & Rumah Dennis \\
\hline Jan & 227 & 181 \\
\hline Feb & 231 & 183 \\
\hline Mar & 212 & 157 \\
\hline April & 196 & 160 \\
\hline May & 215 & 171 \\
\hline Jun & 213 & 172 \\
\hline Jul & 214 & 168 \\
\hline Aug & 218 & 175 \\
\hline Sept & 214 & 164 \\
\hline Oct & 199 & 167 \\
\hline Nov & 236 & 177 \\
\hline Dec & 223 & 179 \\
\hline Average & 216.5 & 171.17 \\
\hline
\end{tabular}

\section{Conclusion}

A hybrid BPL has been implemented in the Bawang Assan community. The implementation of the BPL pilot project was a success and has helped in narrow the gap between the rural community and the rest of the world. Based on result presented in section 4, both longhouses can now have access to the internet with reasonable continuous connectivity similar to an average DSL [15]. However, referring to Table 3, the total costing for the BPL pilot project at Bawang Assan deployment is estimated at RM350K. Such high cost is due to the needs for fiberisation between the communication tower to the backhaul services via the nearest fiber connectivity. But then again, the backhaul fiberisation is considered as one-off installation and can be cater to the rural community nearby if ever there is a future expansion. Though, the costing might be different depending on the location deployment and the nature of the terrain. Many of the main road that link to the rural area in Sarawak has fiber line run through making it possible to lessen the overall costing substantially. 
Table 3. Total costing for the installation of BPL for Rumah Jimbun and Rumah Dennis

\begin{tabular}{|c|l|c|}
\hline No & \multicolumn{1}{|c|}{ Items } & $\begin{array}{c}|c| \\
\text { Amount } \\
\text { (RM) }\end{array}$ \\
\hline 1 & $\begin{array}{l}\text { Equipment (Hardware, software \& } \\
\text { licensing) }\end{array}$ & 110,439 \\
\hline 2 & Technical consultancy (Vendors) & 111,558 \\
\hline 3 & $\begin{array}{l}\text { Backhaul service contribution to } \\
\text { Sacofa }\end{array}$ & 55,000 \\
\hline 4 & $\begin{array}{l}\text { Installation and materials \& Other } \\
\text { miscellaneous }\end{array}$ & 80,814 \\
\hline & \multicolumn{2}{|c}{ Total } \\
\hline
\end{tabular}

Nevertheless, since the BPL deployment it enables the locals to experience the possibility of worldwide communication and information sharing by making use of the infrastructure from the existing powerline. The community has also been exposed to various technologies that help to improve their day to day life. For example, an e-tourism web portal has been developed to manage the once manually promoted homestay. Online marketing, booking and information dissemination are now possible and have assisted in boosting the local economic growth. The local community can now use various social media services such as Internet, voice, video and other applications either for promotional works or entertainment purposes. Apart from that, an online surveillance camera has also been install for the security and safety of the community at Bawang Assan. The continuous live stream of video feed shows that it is a success to use BPL enable the operation of an IP camera at longhouse similar to an urban setting. Therefore, BPL connectivity can be presented as a beneficial solution in addressing the problems of social and physical isolation in rural communities as well as bridging their lifestyle toward a modern and comfortable environment.

This BPL pilot project is a collaboration between three (3) industrial partners and one (1) institution of higher learning; being, Datasonic Technologies Sdn Bhd (Datasonic) as technology provider; Sarawak Energy Berhad (SEB) as the owner of the electricity service line and power producer for the state of Sarawak; Sacofa Sdn Bhd (Sacofa) as an internet service provider and University College of Technology Sarawak (UCTS) as project leader and provider of subject matter experts (SMEs) to test new potential technology for internet access in the rural area of Sarawak. Our heartfelt gratitude extends towards the representative from the Bawang Assan longhouses community, Mr. Marcathy anak Gindau and the people of Rumah Jimbun and Rumah Dennis for their full cooperation.

\section{References}

1. Harvey Lehpamer, Introduction to Power Utility Communication, Artech House Publishers, ISBN13:978-1-63081-006-1 (2016)
2. Sarawak Digital Economy Strategy 2018-2022, Accessed on: March 13, 2020. [Online]. Available: https://www.scope.net.my/wpcontent/uploads/2019/10/digitaleconomybookletmin.pdf

3. H. R Singh \& S. Gupta, Broadband Communication over Power Lines: Issues, Challenges and Opportunities, International Journal of Advanced Research in Computer Science. ISSN No. 09765697. Volume 7, No. 7 (Nov-Dec 2016)

4. F. Hashiesh \& P. Soukal, A Proposed Broad Power Line Communication System for Smart Grid Application in a Typical Egyptian Network, 17th Telecommunication forum TELFPR 2009, Serbia, Belgrade (November 24-26, 2009)

5. Businesswire, Russia Fixed Broadband Market Statistics and Analyses Report 2019, August 19, 2019. Accessed on: March 13, 2020. [Online]. Available:

https://www.businesswire.com/news/home/2019081 9005409/en/Russia-Fixed-Broadband-MarketStatistics-Analyses-Report (2019)

6. Markets and Markets, Power Line Communication Market by Offering (Hardware, Software, and Services), Frequency (Narrowband, and Broadband), Application (Energy Management and Smart Grid, and Indoor Networking), Vertical, and Geography Global Forecast to 2023, December 2017. Accessed on: March 4, 2020. [Online]. Available: https://www.marketsandmarkets.com/MarketReports/power-line-communication-plc-market912.html (2017)

7. MyBroadband, Ghanaian broadband powerline test, July 2005, Accessed on: March 7, 2020. [Online]. Available: https://mybroadband.co.za/nephp/500.html (2005)

8. P. Adepoju, Ghana's public electricity company to deploy fiber, October 8, 2019, Accessed on: March 7, 2020. [Online]. Available: https://itweb.africa/content/O2rQGMAnrYlqd1ea (2019)

9. Sujatha.k, S. et al., BROAD BAND OVER POWERLINE: Provides Internet Facility To Remote Areas, International Journal of Pure and Applied Mathematics, Volume 117 No. 22 2017, 185-188, ISSN: 1314-3395 (2017)

10. A. Olandres, Telstra teams up with Meralco for Gigabit Internet-over-Powerline, April 1, 2016, Accessed on: March 8, 2020. [Online]. Available: https://www.yugatech.com/rumors/telstra-teams-upwith-meralco-for-gigabit-internet-overpowerline/\#sthash.9YVqJuna.dpbs (2016)

11. L. T. Berger et al., MIMO Power Line Communications: Narrow and Broadband Standards, EMC, and advanced processing, CRC Press, Inc ISBN 978-1-4665-5752-9

12. A. M. Sarafi, G. I. Tsiropoulos and P. G. Cottis, "Hybrid wireless-broadband over power lines: A promising broadband solution in rural areas," in 
IEEE Communications Magazine, vol. 47, no. 11, pp. 140-147 (November 2009)

13. Industry Canada Spectrum Management and Telecommunication. Consulataion Paper on Broad over Power Line (BPL) Communication Systems. SMSE-005-5 July 2005. (2005)

14. Malaysian Communications and Multimedia Commission (MCMC), Network Performance
Report 2019, Measurig Malaysia Broadband and voice performance. [Online]. Available: https://www.mcmc.gov.my/skmmgovmy/media/Gen $\mathrm{eral} / \mathrm{pdf} / \mathrm{QoS}$ Network-Performance-Report2019.pdf (2019)

15. International Telecommunication Union, The State of Broadband: Broadband as a Foundation for Sustainable Development, September 2019 